Article

\title{
Correlation of Plastic Strain Energy and Acoustic Emission Energy in Reinforced Concrete Structures
}

\author{
Francisco Sagasta ${ }^{1, *}$, Amadeo Benavent-Climent ${ }^{2}$, Andrés Roldán ${ }^{3}$ and Antolino Gallego ${ }^{1}$ \\ 1 Department of Applied Physics, University of Granada, Granada 18071, Spain; antolino@ugr.es \\ 2 Department of Mechanical Engineering, Polytechnic University of Madrid, Madrid 28006, Spain; \\ amadeo.benavent@upm.es \\ 3 Department of Electronics and Computer Technology, University of Granada, Granada 18071, Spain; \\ amroldan@ugr.es \\ * Correspondence: sagasta@ugr.es; Tel.: +3495-8249-508
}

Academic Editors: Dimitrios G. Aggelis and Nathalie Godin

Received: 26 December 2015; Accepted: 25 February 2016; Published: 16 March 2016

\begin{abstract}
This paper presents a comparison of the acoustic emission (AE) energy and the plastic strain energy released by some reinforced concrete (RC) specimens subjected to cyclic or seismic loadings. AE energy is calculated, after proper filtering procedures, using the signals recorded by several AE low frequency sensors $(25-100 \mathrm{kHz})$ attached on the specimens. Plastic strain energy is obtained by integrating the load displacement curves drawn from the measurements recorded during the test. Presented are the results obtained for: (i) two beams (with and without an artificial notch) and a beam-column connection subjected to several cycles of imposed flexural deformations; (ii) a reinforced concrete slab supported by four steel columns, and a reinforced concrete frame structure, both of the latter are subjected to seismic simulations with a uniaxial shaking table. The main contribution of this paper, which is a review of some papers previously published by the authors, is to highlight that, in all cases, a very good correlation is found between AE energy and plastic strain energy, until the onset of yielding in the reinforcing steel. After yielding, the AE energy is consistently lower than the plastic strain energy. The reason is that the plastic strain energy is the sum of the contribution of concrete and steel, while the AE energy acquired with thresholds higher than $35 \mathrm{~dB}_{\mathrm{AE}}$ captures only the contribution of the concrete cracking, not the steel plastic deformation. This good correlation between the two energies before the yielding point also lends credibility to the use of AE energy as a parameter for concrete damage evaluation in the context of structural health monitoring.
\end{abstract}

Keywords: acoustic emission; reinforced concrete structures; earthquakes; damage evaluation

\section{Introduction}

Reinforced concrete (RC) structural elements develop several damage mechanisms when subjected to static/dynamic, monotonic/cyclic loadings. Before the onset of yielding of the reinforcing steel, concrete damage is associated with: (i) the opening of new cracks or the extension of existing ones when the tension stress exceeds the tensile strength of the concrete; (ii) the friction between the planes of fracture after cracking; or (iii) the concrete cracking under compressive stress. When cyclic loading is caused for example by earthquakes, concrete degradation due to cracking eventually results in cumulative damage (low-cycle fatigue damage) to the structural RC components and leads to a state in which repair becomes necessary. One serious consequence of concrete degradation under cyclic loading is the slip between the reinforcing steel bars and the surrounding concrete.

Evaluating this damage in concrete is not easy because RC structures are commonly covered up by non-structural elements (brick veneers, casings, cement plasters, stuccos, etc.). Such elements 
make simple visual inspection complicated. Moreover, visual inspection provides only qualitative information on the "apparent" damage, but no information on the "cumulative" damage resulting from numerous cycles of imposed deformations. It is here where non-destructive techniques play an important role. Among them, the measurement, recording and analysis of Acoustic Emission (AE) signals prove very effective [1-4]. When applying AE techniques to damage evaluation, it is of paramount importance [5-11]: (i) to discriminate relevant signals from spurious AE records; and (ii) to correlate AE with a well-established index of mechanical damage. The AE may be characterized in terms of the so-called MARSE (Mean Measured Area under the Rectified Signal Envelope) energy [2]. Meanwhile, the energy dissipated by a structure through plastic strain deformations (irreversible deformations) is commonly recognized as a good indicator of damage. This paper summarizes several research initiatives that prove there is a very good correlation between AE energy calculated from the $\mathrm{AE}$ signals, and the plastic strain energy dissipated by concrete. Based on this correlation, the level of damage in an RC structure can be assessed from the $\mathrm{AE}$ records. The correlation is demonstrated under relatively simple loading conditions, i.e., static and monotonic loadings [12,13], yet also under extremely cumbersome loads such as random dynamic cyclic loading caused by earthquakes [13-19]. The AE signals recorded during a seismic event are extraordinarily complex; and unveiling their relation with the damage accumulated on the structure requires considerable post-processing work $[13,16,18-20]$.

\section{Cyclic Loading}

\subsection{RC Beams}

Firstly, a $100 \times 100 \times 1000 \mathrm{~mm}^{3}$ RC beam (Figure 1) was built and subjected to three-point bending tests [13]. Concrete compressive strength was $25 \mathrm{MPa}$. Reinforcement consisted of four longitudinal bars of $4 \mathrm{~mm}$ thickness and $76 \times 76 \mathrm{~mm}^{2}$ square stirrups. Reinforcement steel yield strength was $500 \mathrm{MPa}$.

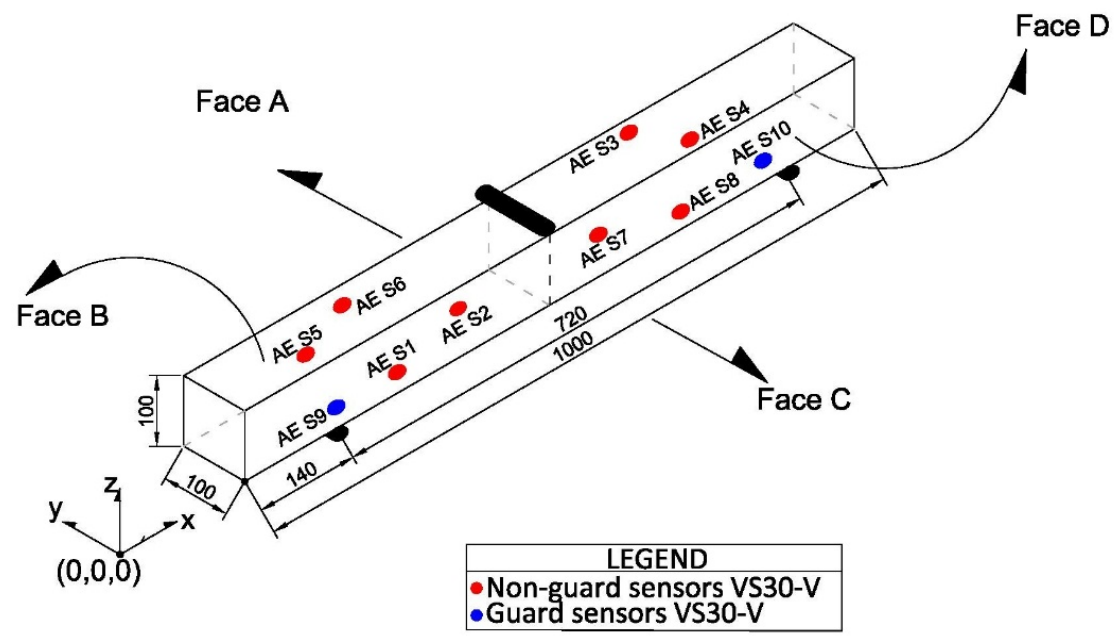

Figure 1. Undamaged Reinforced Concrete $(\mathrm{RC})$ beam and ten Acoustic Emission (AE) sensors. S1 and S2 on face C; S3 and S4 on face B; S5 and S6 on face A; S7 and S8 on face D. Distances in mm.

Applied force, $Q$, and the corresponding vertical displacement, $\delta$, were measured with a load cell and a displacement transducer. AE signals were acquired with ten channels of AMSY-5 equipment using ten VS30-V sensors (Vallen Systeme, Icking, Germany) with an almost flat bandwidth response in low frequency $(25-100 \mathrm{kHz})$. Sampling frequency was set at $5 \mathrm{MHz}$, and the number of samples per signal was 4096 . The threshold used was $35.1 \mathrm{~dB}_{\mathrm{AE}}$. Sensors S9 and $\mathrm{S} 10$ were configured as guard sensors to eliminate noise generated by friction at the supports. After recording, only signals passing the guard sensors and a filter based on the Root Mean Square (RMS) (explained in more detail in [13]) were taken into account during the analysis. 
The bending test was carried out by applying a history of incremental load cycles controlled by force (Figure 2). Each cycle comprises three branches: loading, holding load and unloading, which are represented in Figure 2 by sets of three consecutive segments separated by a segment of null load.

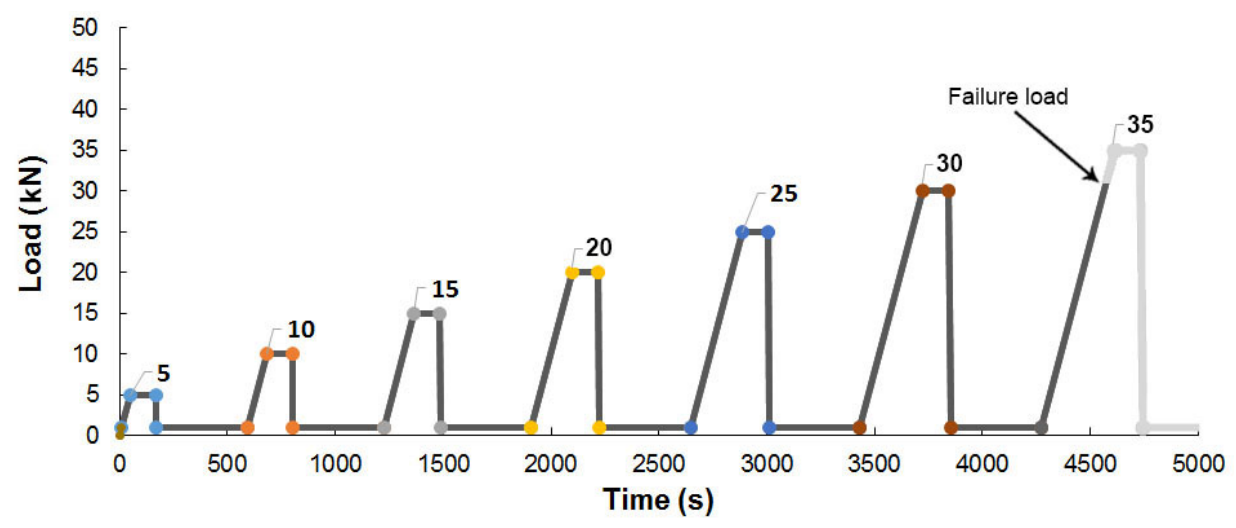

Figure 2. Cycle loading applied to the beam without notch.

Final failure occurred at $Q=30.72 \mathrm{kN}$. Figure 3 shows the load-displacement and load-curvature diagrams. Residual plastic deformations are clearly observed from the initial cycles, indicating that damage took place even in the earlier cycles. This damage likewise results in a degradation of stiffness (Figure 4). This figure shows that for cycles 1,2 and 3, the variation of stiffness between the loading and unloading branches was not significant. However, from cycle 4 onward, this variation becomes more noticeable. Thus, from Figures 3 and 4 it follows that the reinforcement steel began to plastify during cycle 4 . The stiffness degradation became more pronounced as the load increased from cycle 5 onward.

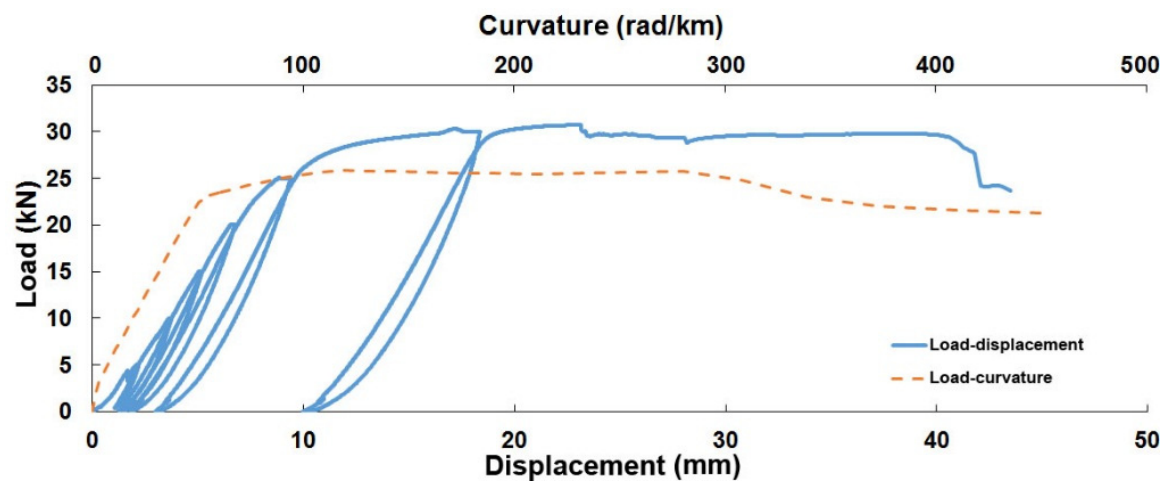

Figure 3. Load-curvature (dashed line) and load-displacement diagrams (solid line).

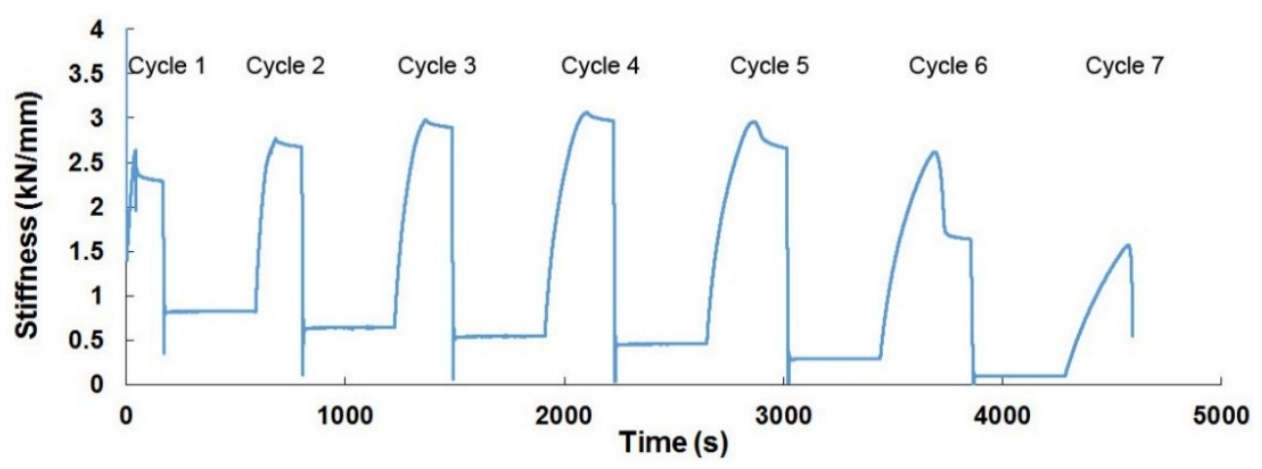

Figure 4. Stiffness degradation of the beam without notch. 
Accumulated AE MARSE energy, $E^{A E}$, was calculated for the first hit of the events constructed with sensors S1-S8 [13] (Figure 5). In this figure, the plastic strain energy $W_{P}$ dissipated by the specimen is also included. Both $E^{A E}$ and $W_{P}$ were normalized by their respective values $E_{0}^{A E}$ and $W_{P, 0}$ at the onset of yielding in the steel reinforcement, referred to hereafter as $t_{0}$. $W_{P}$ was obtained by integrating the load-displacement curve $(Q-\delta) . W_{P}$ is the sum of the energy dissipated by the concrete, $W_{P C}$, and the energy dissipated by the steel, $W_{P S}$, as

$$
\begin{gathered}
W_{P}=W_{P_{c}} \text { if } t<t_{0} \\
W_{P}=W_{P_{c}}+W_{P_{s}} \text { if } t \geqslant t_{0} .
\end{gathered}
$$

AE energy is also a double contribution of concrete and steel. However, with the AE threshold used $(35.1 \mathrm{~dB})$ during acquisition, the very low amplitude AE proceeding from the plastic strain of steel cannot be recorded, i.e.,

$$
E^{A E}=E_{c}^{A E}+E_{s}^{A E} \cong E_{c}^{A E} .
$$

As observed in Figure 5, before the yielding point, a very good correlation exists between $E^{A E} / E_{0}^{A E}$ and $W_{P} / W_{P, 0}$. However, after this point, $E^{A E}$ is always lower than $W_{P}$. Moreover, the decreasing of AE energy - and thus its separation from the plastic strain energy-is in good agreement with the results reported in [21], i.e., AE energy decreases as the energy absorbed by the reinforcement through plastic deformations increases. This result also supports the increase of the $b$-value at the onset of yielding in the steel reinforcement [13]. In sum, it is held that

$$
\begin{aligned}
& W_{P} \sim E^{A E} \text { if } t<t_{0} \\
& W_{P}>E^{A E} \text { if } t \geqslant t_{0},
\end{aligned}
$$

which is in very good agreement with Equations (1) and (2).

Secondly, a $100 \times 100 \times 1600 \mathrm{~mm}^{3}$ beam with an artificial notch in the middle was built and subjected to a three-point bending test (see Figure 6) [13]. Concrete, steel and reinforcement were similar to those of the previous beam. The $5 \times 10 \mathrm{~mm}^{2}$ notch was made according to [22]. Three VS30-V AE sensors were placed at distances of 20,40 and $60 \mathrm{~cm}$ from the middle of the notch. Sensors 4 and 5 were configured as guards and only signals that passed the RMS filter were taken into account during analysis [13].

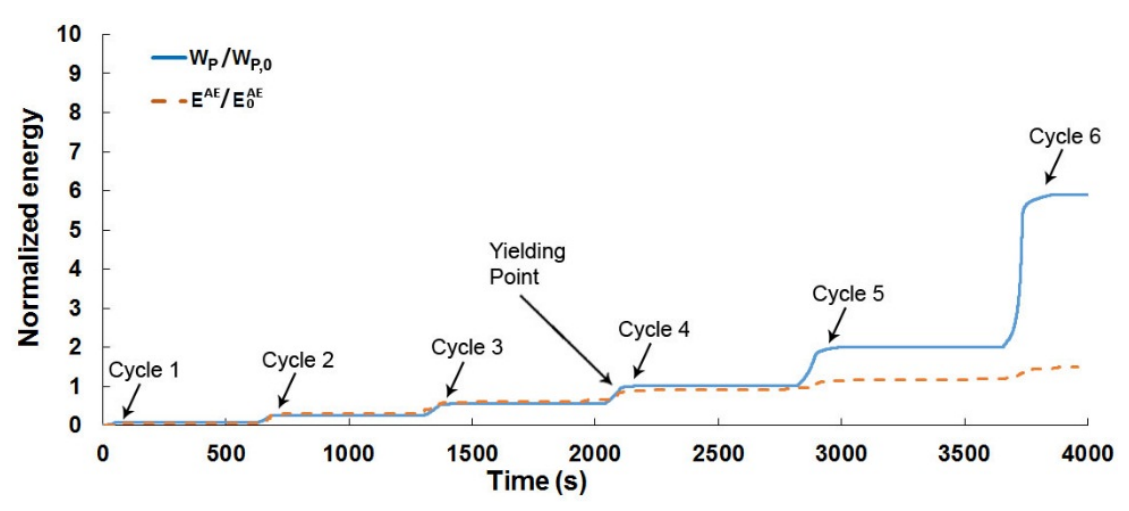

Figure 5. Accumulated AE energy (dashed line) and accumulated hysteretic strain energy (solid line). RC beam without notch. 


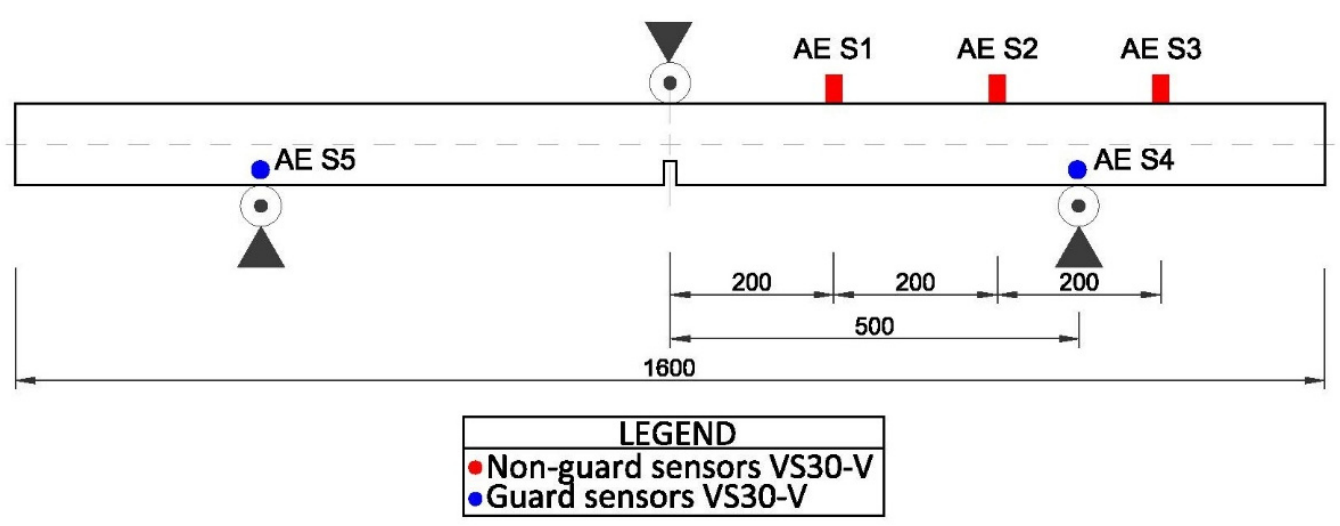

Figure 6. Notched RC beam tested and AE sensors. Distances in $\mathrm{mm}$.

The bending test entailed applying incremental load cycles by force control. Cycles were proportional to each other, with a variation of the maximum load of $4 \mathrm{kN}$ per cycle (see Figure 7). Final failure occurred at $Q=20.3 \mathrm{kN}$. Figure 8 shows the load-displacement and load-curvature diagrams, while degradation of stiffness in each cycle is plotted in Figure 9. Figures 8 and 9 suggest that the yielding point $\left(t_{0}\right)$ was probably reached near the end of cycle 3.

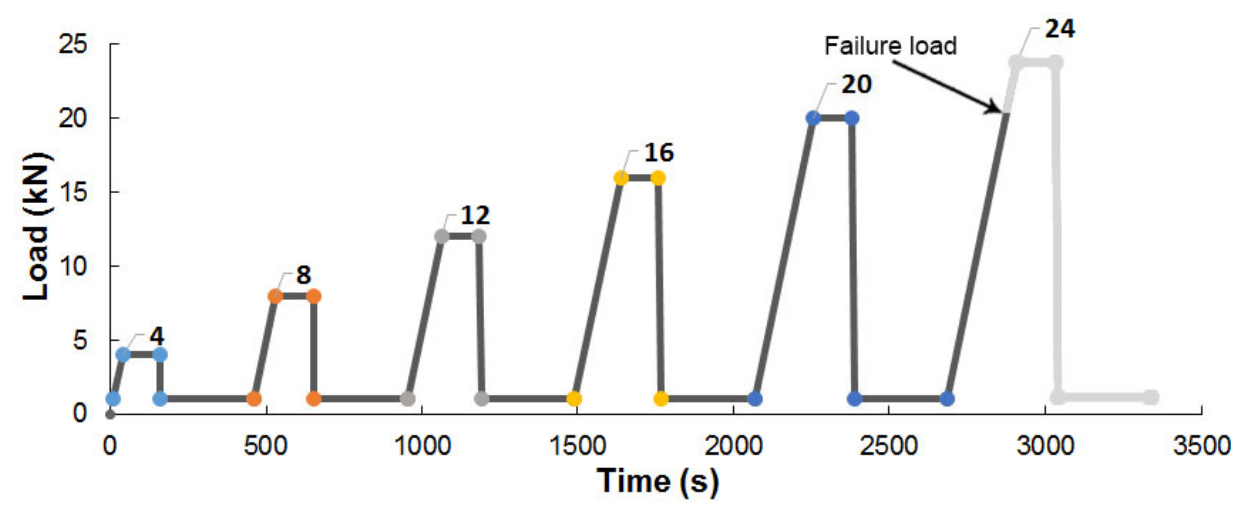

Figure 7. Cycle loading applied to beam with notch.

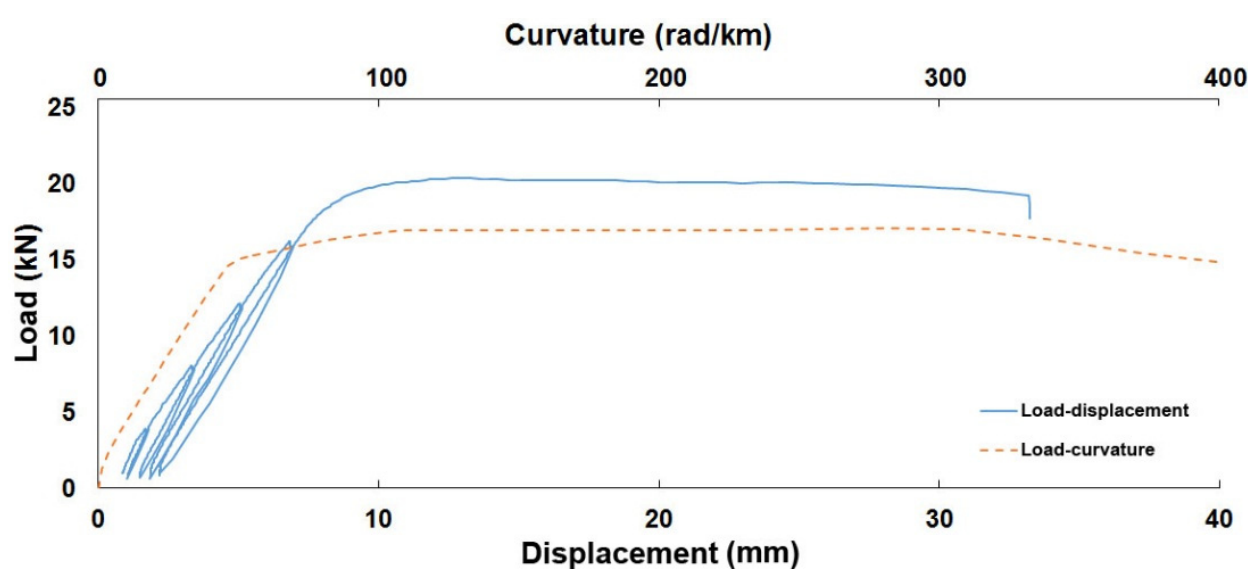

Figure 8. Load-curvature (dashed line) and load-displacement diagrams (solid line). 


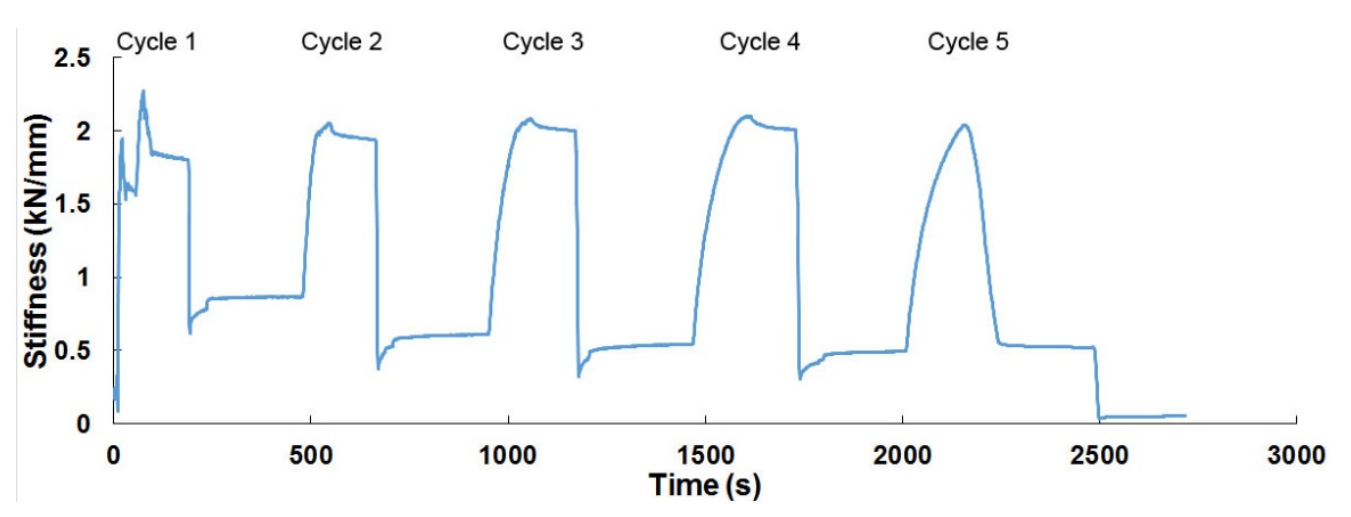

Figure 9. Stiffness degradation of the notched beam.

Accumulated AE MARSE energy, $E^{A E}$, was also calculated for the first-hit of the events constructed with sensors $S 1$ to $S 3$ [13]. Figure 10 shows both energies, $E^{A E}$ and $W_{P}$, normalized by their respective values $E_{0}^{A E}$ and $W_{P, 0}$ at the onset of yielding of the steel reinforcement, $t_{0}$. The result observed coincides with that of the unnotched beam, i.e., there is a very good correlation between $E^{A E}$ and $W_{P}$ until $t_{0}$ and a divergence of the two energies after this point.

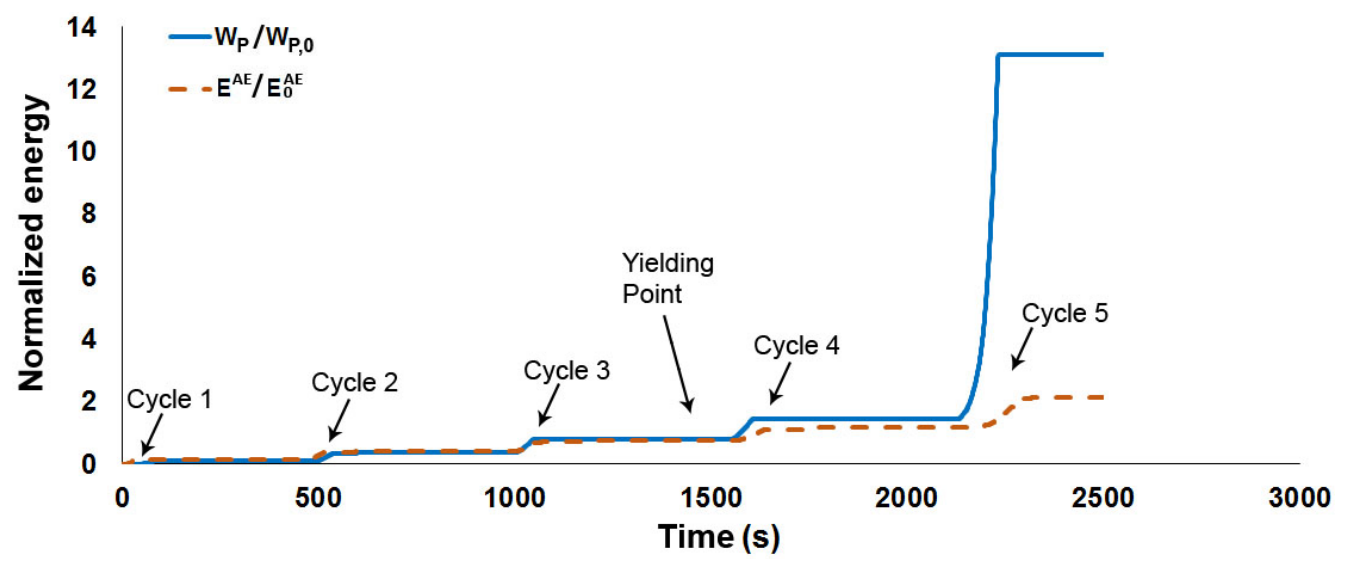

Figure 10. Accumulated AE energy (dashed line) and accumulated hysteretic strain energy (solid line). RC beam with notch.

\subsection{Beam-Column Connection}

A 3/5 scale specimen was constructed to represent an exterior wide beam-column connection in a prototype RC moment-resisting frame with six stories and four bays. The prototype building was designed assuming a location in the earthquake-prone southern part of Spain. The specimen corresponds to the second story of the building. The steel yield stress was $404 \mathrm{MPa}$, and the concrete compressive strength $24.9 \mathrm{MPa}$ [12]. The test model was installed in the loading machine shown in Figure 11, reproducing the actual boundary conditions of the subassemblage within the RC frame under lateral loads. Gravity loading was simulated by the combination of wide beam self-weight and sand bags of total weight $40 \mathrm{kN}$ placed on the beam, plus an axial force applied to the column of $214 \mathrm{kN}$ by means of two post-tensioned rods.

Subsequently, cyclic horizontal forced displacements were applied automatically by the actuator following the scheme shown in Figure 12a, which is based on the ATC-24 loading protocol [23], until failure. The amplitude of the cycles was made constant within each set, but it increased with every consecutive set of cycles, following the sequence $0.5 \Delta y, 0.75 \Delta y, 1.0 \Delta y, 2 \Delta y, 3 \Delta y, 4 \Delta y$ and so on, where $\Delta y$ is the quotient between the predicted lateral displacement at the first yielding of the reinforcing steel and the total height of the column $(180 \mathrm{~cm})$ expressed as a percentage (drift-ratio). 


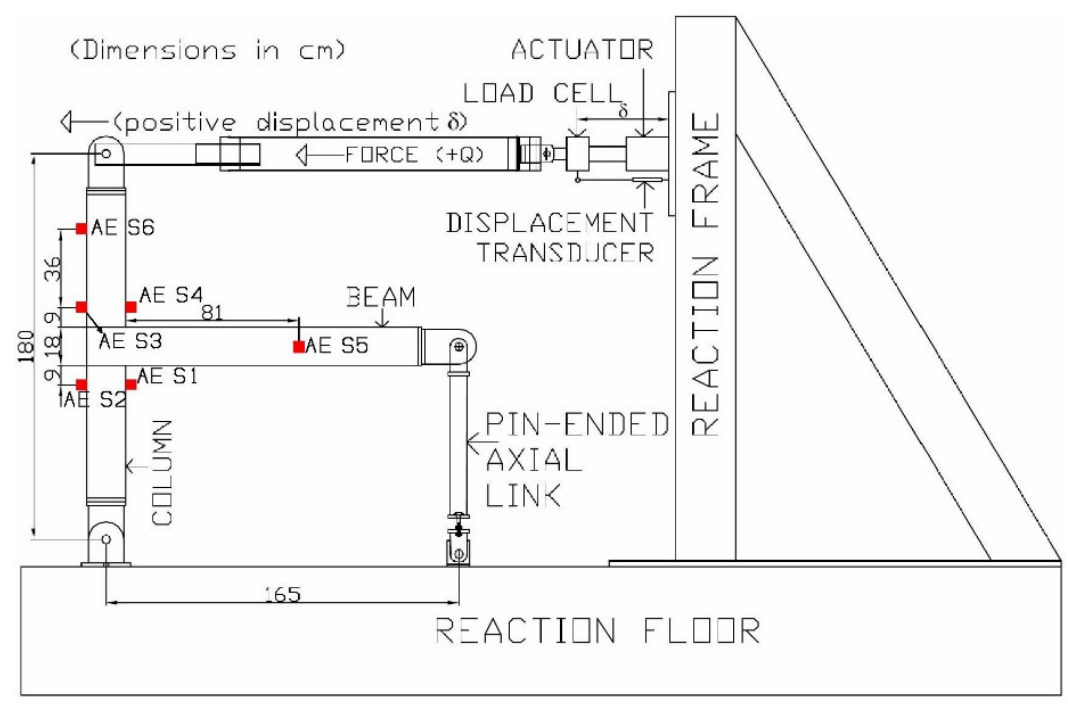

Figure 11. Experimental set up for the beam-column connection subjected to cycling loads.

A load cell and a displacement transducer installed on the actuator measured the overall horizontal force, $Q$, and the corresponding horizontal displacement, $\delta$, while strain gauges attached to the reinforcing steel measured the corresponding strains (Figure 12b). Six AE low-frequency VS30-V sensors (Figure 11) were placed on each specimen. In all the channels, $25-180 \mathrm{kHz}$ pass filters were used; signals were preamplified $34 \mathrm{~dB}_{\mathrm{AE}}$, and $40 \mathrm{~dB}_{\mathrm{AE}}$ was set as the acquisition threshold.

a) Displacement $\delta(\mathrm{mm})$
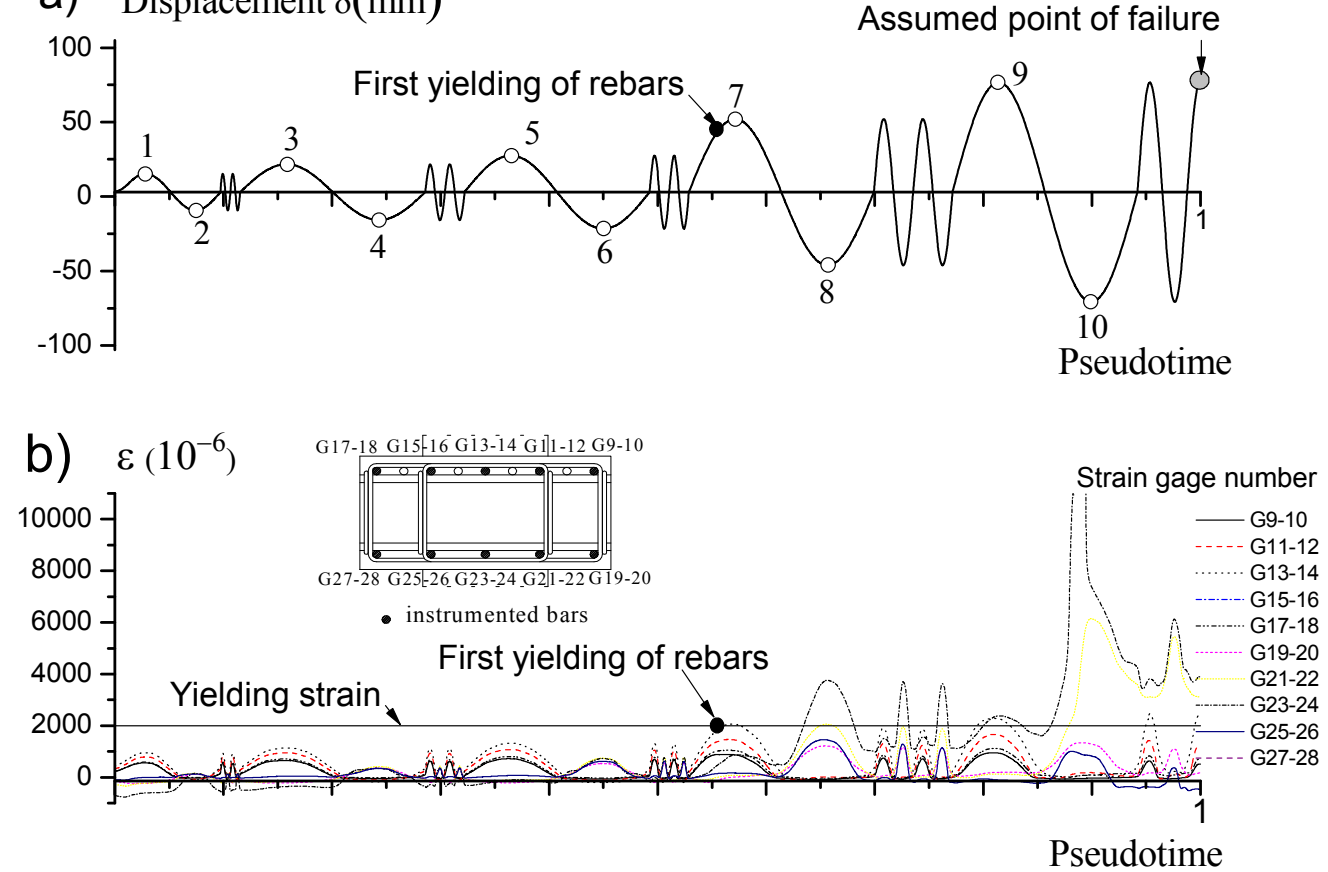

Figure 12. Displacement history applied to beam-column connection (a) and corresponding strains in gauges (b).

Figure $12 \mathrm{~b}$ shows the strains recorded by the gauges fixed to the longitudinal reinforcing bars of the beam at the column face (i.e., at the section of maximum bending moment of the beam). The solid horizontal line indicates the strain corresponding to yielding. It is observed that the steel reinforcement remained elastic (i.e., undamaged) during the first two sets of cycles. Figure 13 shows the curves of overall load-displacement, $Q-\delta$, obtained from the tests. The solid circle indicates the onset of 
plastic deformations in the longitudinal reinforcement, which occurred before the maximum lateral strength was attained. Failure was assumed to occur when the load reached at the peak displacement of a given cycle was lesser than $75 \%$ of the maximum load attained by the specimen in previous cycles. This percentage may be considered as the limit of the "usable" capacity of the member [24].

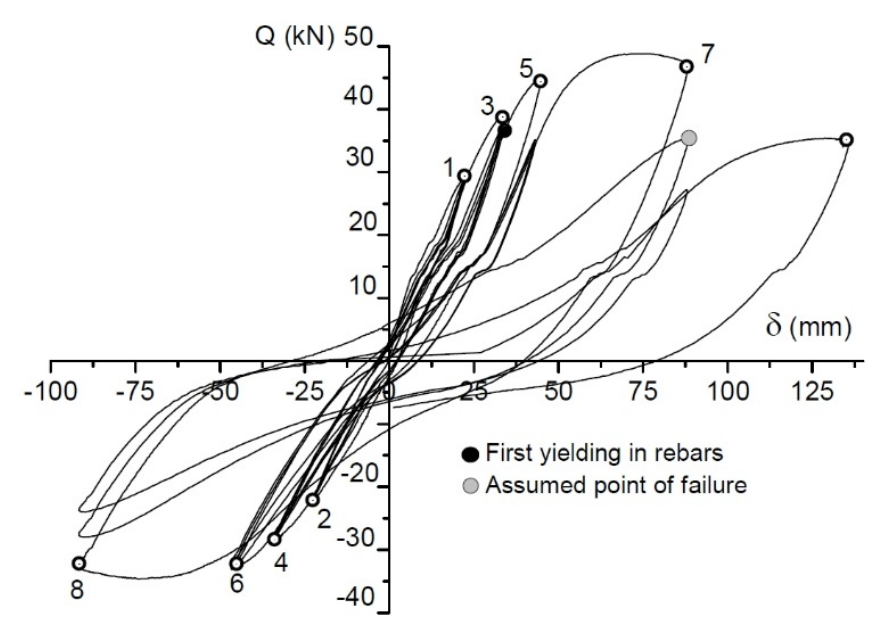

Figure 13. Load-displacement curves of beam-column connection.

The accumulated AE MARSE energy, $E^{A E}$, was calculated for all sensors. Figure 14 displays with dashed lines the $E^{A E}$ calculated from the signals recorded by sensors one (on the column) and five (on the beam) [12]. As seen in this figure, the overall plastic strain energy $W_{P}$ dissipated is superimposed by solid lines. Both $E^{A E}$ and $W_{P}$ were normalized by their respective values $E_{0}^{A E}$ and $W_{P, 0}$ at the onset of yielding in the steel reinforcement, timed at $t_{0}$. Once again, there is a very good correlation between $E^{A E}$ and $W_{P}$ until $t_{0}$. After this point, however, $E^{A E}$ is always lower than $W_{P}$, which is again in very good agreement with Equations (1) and (2).
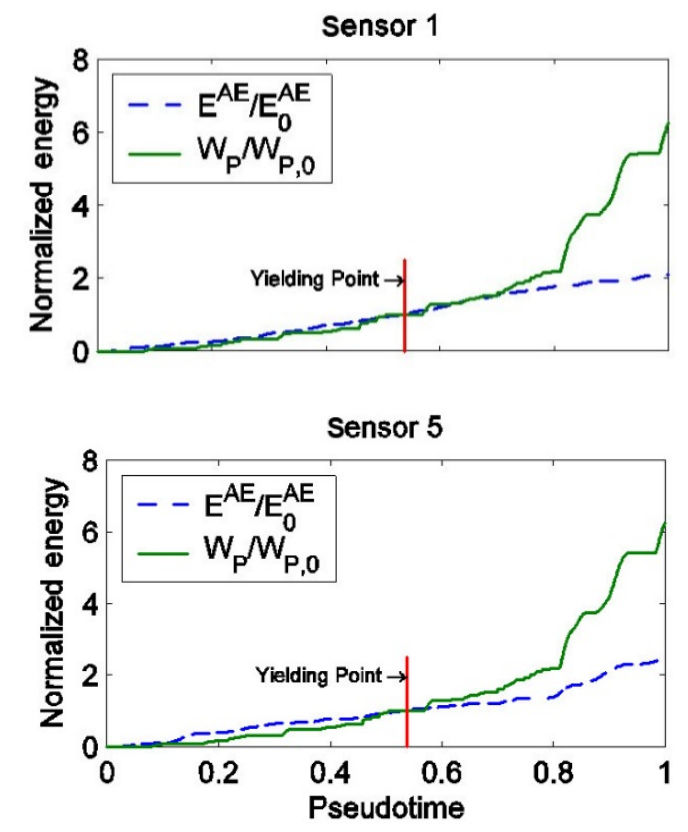

Figure 14. Accumulated AE energy (dashed line) and accumulated hysteretic strain energy (solid line). Beam-column connection. 
Since, in specimens subjected to cyclic loadings, the load was applied quasi-statically, the low speed of loading made it possible to follow (in most cases by the naked eye) the evolution of different cracking modes. Initially, microcracking started to develop in the tensile side of beams and columns, followed by macroscopic cracks that formed when the tensile strength of concrete was reached. Both flexural and shear cracks were identified, and the former type predominated over the latter during the loading process. In the case of the RC beams reported in Subsection 2.1, flexural cracks (perpendicular to the axis of the member) started at the midspan of the beam. These cracks enlarged as the level of applied force increased and new flexural cracks appeared, extending progressively to both ends. Shear cracks (inclined approximately 45 degrees) were also observed near the points where the load or the reaction forces were applied. In the case of the beam-column connection, flexural cracks developed at the tension sides of beam and columns, and shear cracks were visible in the region where beam and column intersect (commonly known as beam-column joint).

\section{Seismic Loading}

\subsection{RC Slab}

A prototype one-story, one-bay structure $(2.8 \mathrm{~m}$ high and $4.8 \mathrm{~m}$ long) consisting of an RC slab supported on four box-type steel columns was designed following current Spanish codes NCSE-02 and EHE-08. From this prototype structure, the corresponding test model was derived by applying the similarity laws described in [15]. The depth of the slab was $125 \mathrm{~mm}$. It was reinforced with steel meshes: one on the top made with $6 \mathrm{~mm}$ diameter bars spaced $100 \mathrm{~mm}$, and another on the bottom consisting of $10 \mathrm{~mm}$ diameter bars spaced $75 \mathrm{~mm}$. The average yield stress of the reinforcing steel was $467 \mathrm{MPa}$, and the average concrete strength was $23.5 \mathrm{MPa}$. The model was tested with a uniaxial MTS $3 \times 3 \mathrm{~m}^{2}$ shaking table as shown in Figure 15 .

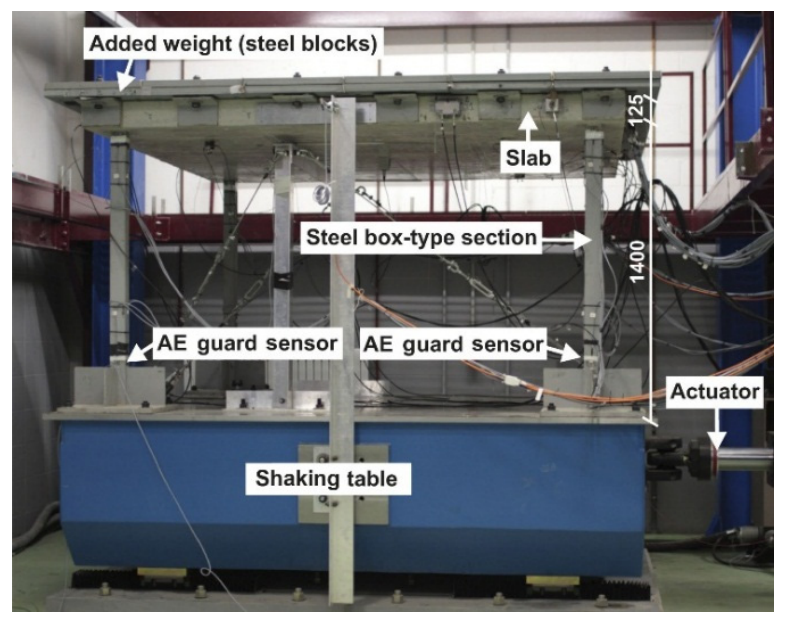

(a)

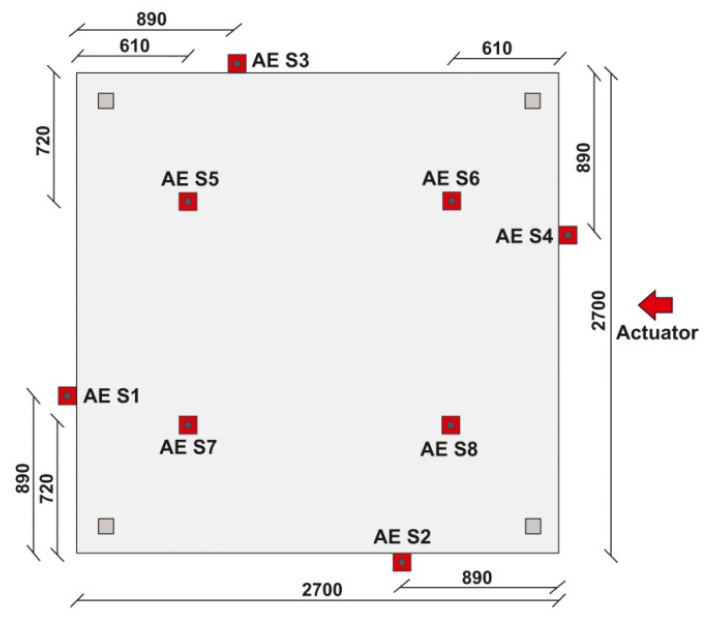

(b)

Figure 15. RC slab with AE sensors (S1 to S8) on the shaking table. (a) Elevation. (b) Plan (bottom view). Distances in $\mathrm{mm}$.

The acceleration record used for the tests reproduced the North-South (NS) component of the 1980 Campano-Lucano earthquake recorded at Calitri (Italy). Two series of seismic simulations were applied to the test model. The same accelerogram was used in all simulations, the scaling factor of the peak accelerations (PA) being the only difference (Figure 16). Displacements, strains and accelerations were acquired simultaneously during each seismic simulation.

Eight VS30-V AE sensors were placed on the specimen at the eight positions indicated in Figure 15. $\mathrm{AE}$ signal acquisition was carried out using a sampling period of $1.6 \mu \mathrm{s}, 45 \mathrm{~dB}_{\mathrm{AE}}$ as the detection threshold and amplifiers of $34 \mathrm{~dB}_{\mathrm{AE}}$. An $\mathrm{AE}$ signal discrimination procedure was applied to prevent 
spurious and friction sources using guard sensors and an RMS filter [18]. The accumulated AE MARSE energy, $E^{A E}$, was calculated for the first-hit of the events constructed with the eight channels [15]. As an example, Figure 17 shows $E^{A E}$ with dashed lines for simulations D1 (before the sliding point of the reinforcement steel inside the concrete) and D2 (after sliding point). In this figure, the overall plastic strain energy $W_{P}$ dissipated is superimposed by solid lines. Both $E^{A E}$ and $W_{P}$ were normalized by their values at the end of each simulation. As seen in Figure 17, for simulation D1, the two energy curves are very well correlated. However, in simulation D2, this correlation is not maintained, the accumulated AE energy being consistently lower than the cumulative strain energy.

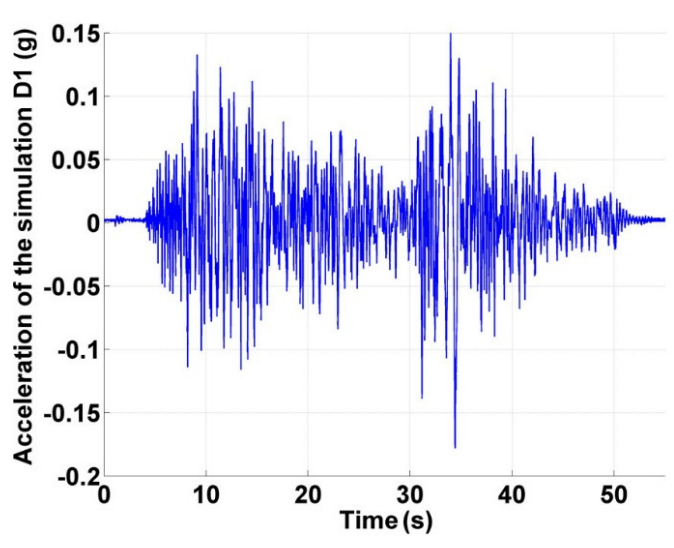

(a)

\begin{tabular}{|c|c|c|}
\hline \multicolumn{2}{|c|}{ TEST SERIES } & \multirow{3}{*}{ PA (g) } \\
\hline 1 & 2 & \\
\hline \multicolumn{2}{|c|}{ Simulation } & \\
\hline A1 & & 0.08 \\
\hline B1 & & 0.10 \\
\hline $\mathrm{C} 1$ & & 0.12 \\
\hline D1 & & 0.19 \\
\hline E1 & & 0.29 \\
\hline F1 & & 0.38 \\
\hline G1 & & 0.44 \\
\hline \multirow[t]{7}{*}{$\mathrm{H} 1$} & & 0.58 \\
\hline & A2 & 0.19 \\
\hline & B2 & 0.38 \\
\hline & $\mathrm{C} 2$ & 0.58 \\
\hline & D2 & 0.66 \\
\hline & E2 & 0.74 \\
\hline & $\mathrm{F} 2$ & 0.95 \\
\hline
\end{tabular}

(b)

Figure 16. (a) Acceleration of Campano-Lucano earthquake scaled at 100\% (Simulation D1); (b) Seismic simulations (name and Peak Acceleration (PA)).
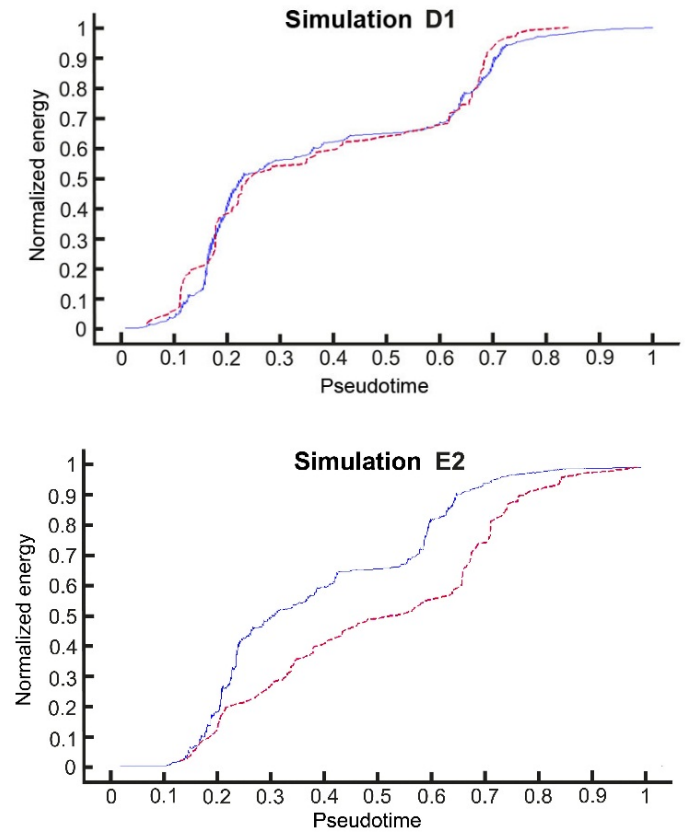

Figure 17. Accumulated AE energy (dashed line) and accumulated plastic strain energy (solid line) obtained for the RC slab. Both were normalized at the end of each simulation. 
Figure 18 represents the final values of both energies obtained in each simulation, normalized by their respective values $E_{0}^{A E}$ and $W_{P, 0}$ at the onset of the sliding point of the steel reinforcement, timed at $t_{0}$. At that moment, the steel columns also began to yield. The $\mathrm{AE}$ threshold used $\left(45 \mathrm{~dB}_{\mathrm{AE}}\right)$ during acquisition could not record the very low amplitude AE proceeding from the plastic strain of steel. This fact justifies the very good correlation between $E^{A E}$ and $W_{P}$ up to $t_{0}$ and the deviation of the two energies after this point, again in very good agreement with Equations (1) and (2).

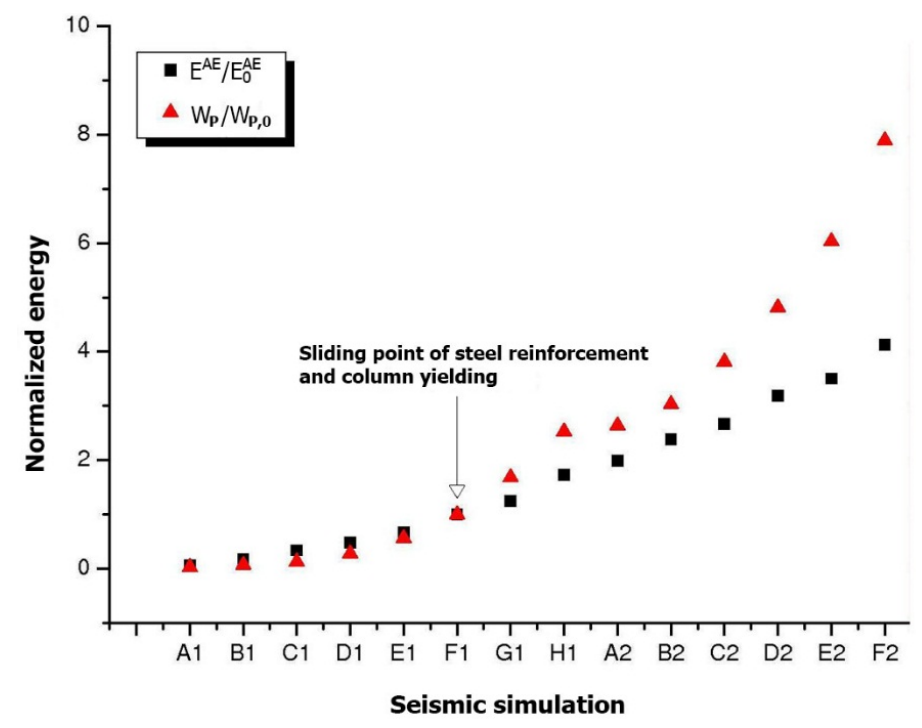

Figure 18. Accumulated AE energy (black square) and accumulated plastic strain energy (red triangle).

RC slab.

\subsection{RC Frame}

A prototype RC building was designed following the current Spanish seismic code NCSE-02, assuming that it was located in Granada (Spain), the most earthquake-prone region in all of Spain. From this prototype, and by applying scale factors, the test model displayed in Figure 19 was projected and constructed $[14,19,20]$. Basically, the test specimen consisted of four RC columns connected by RC beams (Figure 19).

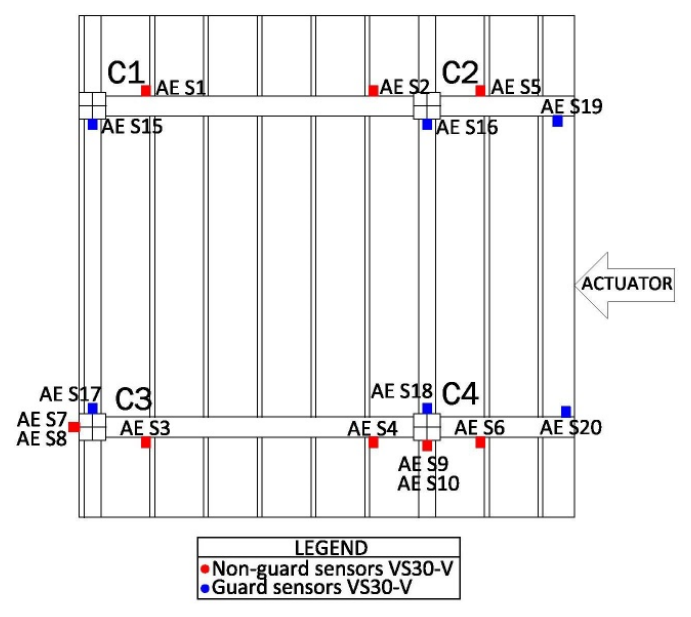

(a)

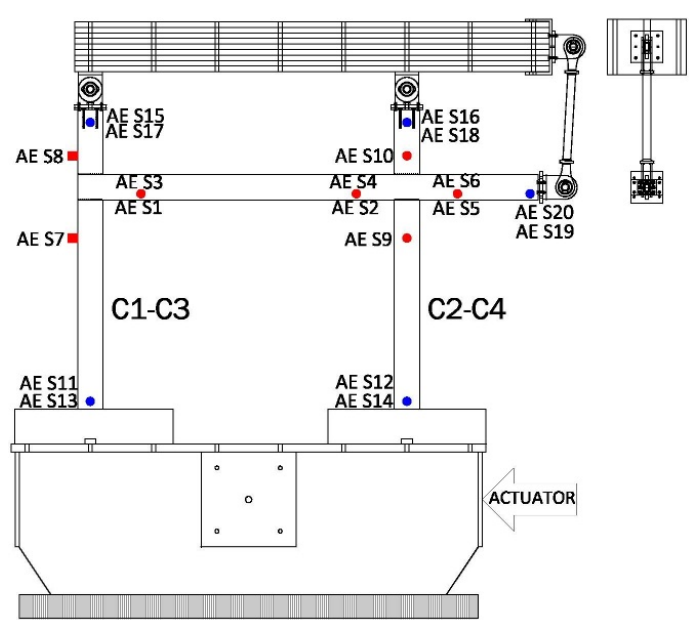

(b)

Figure 19. RC frame with AE sensors (S1 to S20). (a) Plan (bottom view); (b) Elevation. 
AE signals were acquired with twenty VS30-V AE sensors (Figure 19), recording the waveform with a sampling frequency of $2.5 \mathrm{MHz}$ and a detection threshold of $50 \mathrm{~dB}_{\mathrm{AE}}$ and preamplifiers of $34 \mathrm{~dB}_{\mathrm{AE}}$. In addition, the steel reinforcement was instrumented with 192 strain gauges and 10 uniaxial accelerometers, and nine displacement transducers were installed on the RC specimen in order to measure the in-plane translations and the inter-story drifts in the direction of the seismic loading.

The RC frame was subjected to the same earthquake pattern as the RC slab. In this case, five seismic uniaxial tests were consecutively applied to the specimen with steadily increasing values of $P A$, i.e., $50 \%, 50 \% ; 100 \% ; 200 \%$ and $300 \%$. Figure 20 shows the corresponding accelerograms.

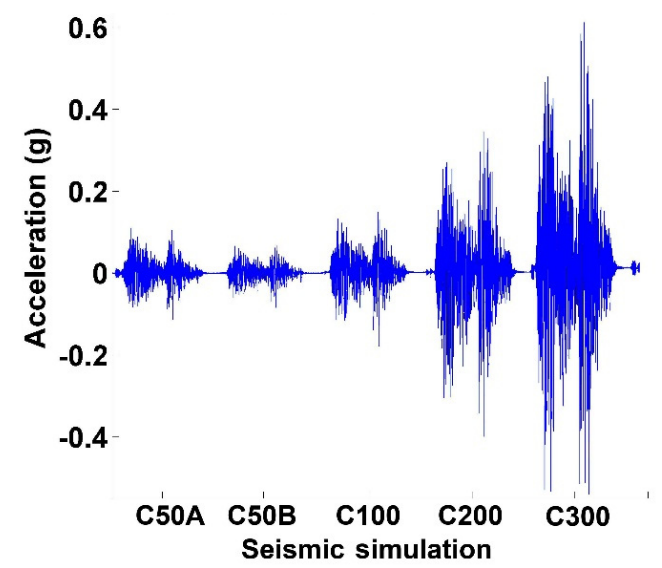

(a)

\begin{tabular}{ccc}
\hline Seismic Simulation & PA (g) & Duration (s) \\
\hline C50A & 0.011 & 50 \\
C50B & 0.083 & 50 \\
C100 & 0.180 & 50 \\
C200 & 0.345 & 50 \\
C300 & 0.580 & 50 \\
\hline
\end{tabular}

(b)

Figure 20. (a)Acceleration of the five seismic simulations applied to the RC frame with the shaking table; (b) Seismic simulations (name, Peak Acceleration (PA) and duration).

A local damage study in the $\mathrm{C} 3$ and $\mathrm{C} 4$ beam-column connections was based on the AE energy generated at the zones around these connections, which are, in fact, the most critical points of the specimen. For interior connection C4, the sensors S2, S6, S9 and S10 were configured to construct the $\mathrm{AE}$ events, and the rest were considered as guard sensors. Likewise, for the exterior column-beam connection C3, only the sensors S3, S7 and S8 were configured to construct the AE events, the rest being considered as guards [19].

The Morlet Continuous Wavelet Transform (CWT) was applied in order to reconstruct AE signals using only scales 18 to 20 , which correspond to the $45-64 \mathrm{kHz}$ frequency band, tentatively assigned to the concrete cracking [16,17]. The accumulated AE MARSE energy, $E^{A E}$, was calculated for the reconstructed AE signals corresponding to the first-hit of events. Results are shown in Figure 21 along with the overall plastic strain energy $\left(W_{P}\right)$ dissipated by the specimen $[13,14]$. Both $E^{A E}$ and $W_{P}$ were normalized by their respective values $E_{0}^{A E}$ and $W_{P, 0}$ at the onset of yielding of the steel reinforcement. Figure 21 reflects the same result as in previous tests, namely a very good correlation between $E^{A E}$ and $W_{P}$ until $t_{0}$, and a divergence of the energies after this point, in very good agreement with Equations (1) and (2). It is worth noting that, besides the good correlation between $E_{0}^{A E}$ and $W_{P, 0}$, it is consistently observed that the development of cracks in concrete reduces the fundamental frequency of vibration of the specimen and increments the fraction of damping $[14,25,26]$. The reduction of the fundamental frequency is due to the decrease of stiffness. The increase of damping is associated with the energy dissipated through friction between the planes of fracture after cracking. Moreover, the accumulated damage (in terms of plastic strain energy) always increases monotonically over time, and the rate of this increase tends to augment with the amplitude of the applied load.

This satisfactory correlation is consistent with the results of other researchers [27-30]. Since in the specimens subjected to seismic loading, the forces were applied dynamically in successive seismic simulations, only macroscopic cracks were observed at the end of each one. These cracks were evident after the first seismic simulation. In subsequent simulations, macroscopic cracks extended and new 
ones developed. In the case of the RC slab, all the cracks identified were of the flexural type. As for the $\mathrm{RC}$ frame, flexural cracks developed at beam and column ends (i.e., near the beam-column joint), and shear cracks were visible only within the beam-column joint.

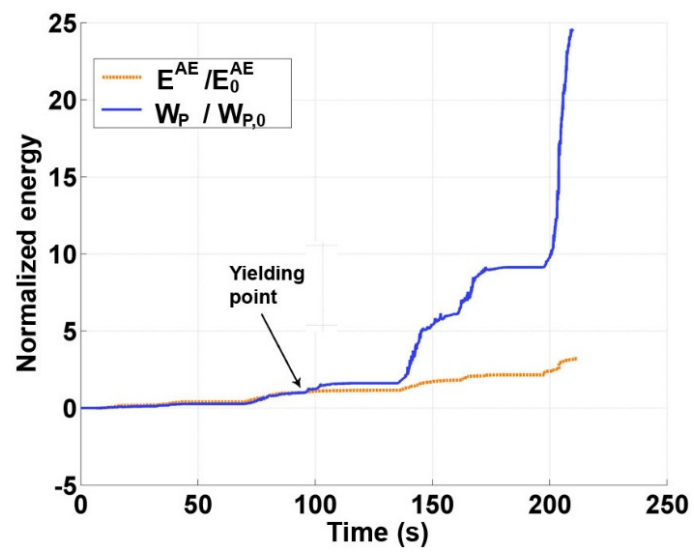

Figure 21. Accumulated AE energy (dashed line) and accumulated plastic strain energy (solid line). RC frame.

\section{Conclusions}

The Acoustic Emission (AE) technique was used to assess damage in several reinforced concrete (RC) elements and structures subjected to different types of loading. Simple beams, beam-column subassemblages, flat-slab structures supported on steel columns, and RC frame structures were tested. The RC elements and structures were subjected to static cyclic loads and randomly applied dynamic loadings. During each test, the AE was recorded by several low-frequency sensors. In addition, forces, accelerations and displacements were measured with load cells, accelerometers and displacement transducers. Analysis of the AE signals served to calculate the AE MARSE energy accumulated throughout the test. By integrating the load-displacement curves, the energy dissipated through plastic deformations was calculated. Plastic strain energy is commonly recognized as a good indicator of damage; and it was found that there is a good correlation between the AE MARSE energy calculated with the AE measurements and the cumulative damage on the concrete measured in terms of plastic strain energy. Such a correlation points to the utility of AE signals for developing damage indices based on AE MARSE energy, as they are capable of assessing the damage in RC structures subjected to different types of loadings. An example of the damage index based on the correlation of the strain and acoustic energies is the Sentry function, proposed in [31], in terms of the logarithmic ratio of both energies. The reason why AE MARSE energy can be utilized for the establishment of damage indices in reinforced concrete (RC) elements is that the failure of RC structural elements is typically due to the degradation (damage) of concrete, not of the reinforcing steel. That is, what typically limits the ultimate capacity of a RC element is the amount of plastic strain energy accumulated in the concrete, not in the reinforcing steel. It is also worth noting that, in a real experiment or in a real structure, calculating the damage index in terms of AE MARSE energy requires an estimation of the final value of the AE MARSE energy (i.e., the value associated with failure). Past research [15,32] ascertained that this estimation can be made on the basis of the information collected from previous experiments and the volume of concrete of the specimen or of the real structure. A change in specimen size does not have appreciable effects on damage patterns, but the volume $V$ of damaged concrete affects the number of AE events as well as the AE MARSE energy; simple relationships that relate AE MARSE energy with $V$ have been proposed [33-36].

Acknowledgments: This research received financial support from the local government of Spain, Consejería de Innovación, Ciencia y Tecnología, projects P07-TEP-02610 and PE12-TEP-02429, from the Spanish National Plan for Scientific Research, Development and Technological Innovation (projects BIA 2005-00591 and DPI 2006-02970), 
and from the Formación del Profesorado Universitario (FPU) Program of Spain's Ministry of Education, Culture and Sports (AP2010-2880).

Author Contributions: All authors contributed to the work presented in this paper, and to the writing of the final manuscript. F.S. and A.R were responsible for the Acoustic Emission and the analysis of the data. A.G. and A.B-C. provided discussion on the testing procedure and the results, and were responsible for the mechanical testing and AE monitoring.

Conflicts of Interest: The authors declare no conflict of interest.

\section{Abbreviations}

The following abbreviations are used in this manuscript:

AE Acoustic Emission

\section{References}

1. Grosse, C.U.; Ohtsu, M. Acoustic Emission Testing; Springer: Berlin, Germany, 2008.

2. Miller, R.K.; Hill, E.K.; Moore, P.O. Acoustic emission testing, NDT Handbook, 3rd ed.; American Society for Nondestructive Testing: Columbus, OH, USA, 2005.

3. Ono, K. Application of acoustic emission for structure diagnosis. Diagnostyka 2011, 2, 3-18.

4. Ohtsu, M. The history and development of acoustic emission in concrete engineering. Mag. Concr. Res. 1996, 48, 321-330. [CrossRef]

5. ElBatanouny, M.; Larosche, A.; Mazzoleni, P.; Ziehl, P.; Matta, F.; Zappa, E. Identification of cracking mechanisms in scaled FRP reinforced concrete beams using acoustic emission. Exp. Mech. 2014, 54, 69-82. [CrossRef]

6. Calabrese, L.; Campanella, G.; Proverbio, E. Identification of corrosion mechanisms by univariate and multivariate statistical analysis during long term acoustic emission monitoring on a pre-stressed concrete beam. Corros. Sci. 2013, 73, 161-171. [CrossRef]

7. Mangual, J.; ElBatanouny, M.; Ziehl, P.; Matta, F. Acoustic-emission-based characterization of corrosion damage in cracked concrete with prestressing strand. ACI Mater. J. 2013, 110, 89-98.

8. ElBatanouny, M.; Ziehl, P.; Larosche, A.; Mangual, J.; Matta, F.; Nanni, A. Acoustic emission monitoring for assessment of prestressed concrete beams. Constr. Build. Mater. 2014, 58, 46-53. [CrossRef]

9. Abdelrahman, A.; ElBatanouny, M.; Ziehl, P.; Fasl, J.; Larosche, C.J.; Fraczek, J. Classification of alkali-silica reaction damage using acoustic emission: A proof-of-concept study. Constr. Build. Mater. 2015, 95, 406-413. [CrossRef]

10. Laroche, A.; Ziehl, P.; Mangual, J. Damage evaluation of prestressed piles to cast in pace bent cap connections with acoustic emission. Eng. Struct. 2015, 84, 184-194. [CrossRef]

11. Abdelrahman, M.; ElBatanouny, M.; Rose, J.; Ziehl, P. Signal processing techniques for filtering acoustic emission data in prestressed concrete. Struct. Health Monit., in press.

12. Benavent-Climent, A.; Castro, E.; Gallego, A. Evaluation of low cycle fatigue damage in RC exterior beam-column subassemblages by acoustic emission. Constr. Build. Mater. 2010, 24, 1830-1842. [CrossRef]

13. Sagasta, F. Evaluación De Daño En Estructuras De Hormigón Armado Sometidas a Cargas Sísmicas Mediante El Método De Emisión Acústica. Ph.D. Thesis, Universidad de Granada, Granada, Spain, 29 January 2016. (In German)

14. Benavent-Climent, A.; Escolano-Margarit, D.; Morillas, L. Shake-table tests of a reinforced concrete frame designed following modern codes: Seismic performance and damage evaluation. Earthq. Eng. Struct. Dyn. 2014, 43, 791-810. [CrossRef]

15. Benavent-Climent, A.; Gallego, A.; Vico, J.M. An acoustic emission energy index for damage evaluation of reinforced concrete slabs under seismic loads. Struct. Health Monit. 2011, 11, 69-81. [CrossRef]

16. Zitto, M.E.; Piotrkowski, R.; Gallego, A.; Sagasta, F.; Benavent-Climent, A. Damage assessed by Wavelet scale bands and $b$-value in dynamical test of a reinforced concrete slab monitored with acoustic emission. Mech. Syst. Signal Process. 2015, 60, 75-89. [CrossRef] 
17. Zitto, M.E.; Piotrkowski, R.; Gallego, A.; Sagasta, F. AE wavelet processing in dynamical tests of a reinforced concrete slab. J. Acoust. Emiss. 2012, 30, 64-75.

18. Sagasta, F.; Torné, J.L.; Sánchez, A.; Gallego, A. Discrimination of acoustic emission signals for damage assessment in a reinforced concrete slab subjected to seismic simulations. Arch. Acoust. 2013, 38, 303-310. [CrossRef]

19. Sagasta, F.; Morillas, L.; Roldán, A.; Benavent-Climent, A.; Gallego, A. Discrimination of AE signals from friction and concrete cracking in a reinforced concrete frame subjected to seismic trainings. In Proceedings of the 6th ECCOMAS Conference on Smart Structures and Materials SMART2013, Turin, Italy, 24-26 June 2013.

20. Sagasta, F.; Benavent-Climent, A.; Fernández-Quirante, T.; Gallego, A. Modified Gutenberg-Richter coefficient for damage evaluation in reinforced concrete structures subjected to seismic simulations on a shaking table. J. Nondestruct. Eval. 2014, 33, 616-631. [CrossRef]

21. Aggelis, D.G.; Soulioti, D.V.; Getselou, E.A.; Barkoula, N.M.; Matikas, T.E. Monitoring of the mechanical behavior of concrete with chemically treated steel fibers by acoustic emission. Constr. Build. Mater. 2013, 48, 1255-1260. [CrossRef]

22. Japanese Industrial Standards (JIS) A 1132. In Method of Making and Curing Concrete Specimens; Japan Concrete Institute Standard: Tokyo, Japan, 2014.

23. Luo, Y.H.; Durrani, A.J. Equivalent beam model for flat-slab buildings-Part II: Exterior connections. ACI Struct. J. 1995, 92, 250-257.

24. Scribner, C.F.; Wight, J.K. Strength decay in reinforced concrete members under load reversals. J. Struct. Division ASCE 1980, 106, 861-875.

25. Benavent-Climent, A.; Morillas, L.; Escolano, D. Seismic performance and damage evaluation of a reinforced concrete frame with hysteretic dampers through shake-table tests. Earthq. Eng. Struct. Dyn. 2014, 43, 2399-2417. [CrossRef]

26. Benavent-Climent, A.; Donaire-Ávila, J.; Oliver-Saiz, E. Shaking table tests of a reinforced concrete waffle-flat plat structure designed following modern codes: Seismic performance and damage evaluation. Earthq. Eng. Struct. Dyn. 2015. [CrossRef]

27. Niccolini, G.; Borla, O.; Accornero, F.; Lacidogna, G.; Carpinteri, A. Scaling in damage by electrical resistance measurements: An application on the terracotta statues of the Sacred Mountain of Varallo Renaissance Complex (Italy). Rend. Lincei-Sci. Fis. 2015, 26, 203-209. [CrossRef]

28. Niccolini, G.; Borla, O.; Lacidogna, G.; Carpinteri, A. Correlated fracture precursors in rocks and cement based materials under stress. In Acoustic, Electromagnetic, Neutron Emissions from Fracture and Earthquakes; Carpinteri, A., Lacidogna, G., Manuello, A., Eds.; Springer International Publishing: Cham, Switzerland, 2016.

29. Carpinteri, A.; Lacidogna, G.; Manuello, A.; Borla, O. Electromagnetic and neutron emissions from brittle rocks failure: Experimental evidence and geological implications. J. SADHANA 2012, 37, 59-78. [CrossRef]

30. Carpinteri, A.; Lacidogna, G.; Manuello, A.; Niccolini, A.; Schiavi, A.; Agosto, A. Mechanical and electromagnetic emissions related to stress-induced cracks. Exp. Tech. 2010, 36, 53-64. [CrossRef]

31. Selman, E.; Ghiami, A.; Alver, N. Study of fracture evolution in FRP-strengthened reinforced concrete beam under cyclic load by acoustic emission technique: An integrated mechanical-acoustic energy approach. Constr. Build. Mater. 2015, 95, 832-841. [CrossRef]

32. Benavent-Climent, A.; Castro, E.; Gallego, A. AE monitoring for damage assessment of RC exterior beam-column subassemblages subjected to cyclic loading. Struct. Health Monit. 2009, 8, 175-189. [CrossRef]

33. Carpinteri, A.; Pugno, N. Fractal fragmentation theory for shape effects on quasi-brittle materials in compression. Mag. Concr. Res. 2002, 54, 473-480. [CrossRef]

34. Carpinteri, A.; Lacidogna, G.; Niccolini, G. Critical behaviour in concrete structures and damage localization by acoustic emission. Key Eng. Mater. 2006, 312, 305-310. [CrossRef]

35. Carpinteri, A.; Lacidogna, G.; Pugno, N. Structural damage diagnosis and life-time assessment by acoustic emission monitoring. Eng. Fract. Mech. 2007, 74, 273-289. [CrossRef]

36. Carpinteri, A.; Lacidogna, G.; Niccolini, G. Fractal analysis of damage detected in concrete structural elements under loading. Chaos Soliton Fract. 2009, 42, 2047-2056. [CrossRef]

(C) 2016 by the authors; licensee MDPI, Basel, Switzerland. This article is an open access article distributed under the terms and conditions of the Creative Commons by Attribution (CC-BY) license (http://creativecommons.org/licenses/by/4.0/). 